$11-2020$

\title{
Advancing Sustainability Education in Business Studies through Digital Service Learning
}

\author{
Stephanie Perkiss \\ University of Wollongong, Australia \\ Stephanos Anastasiadis \\ Polizeiakademie Niedersachsen, Germany \\ Leopold Bayerlein \\ University of New England, Australia \\ Bonnie Dean \\ University of Wollongong, Australia \\ Hannah Jun \\ Ewha Woman's University, South Korea
}

See next page for additional authors

Follow this and additional works at: https://digitalcommons.newhaven.edu/americanbusinessreview

\section{Recommended Citation}

Perkiss, Stephanie; Anastasiadis, Stephanos; Bayerlein, Leopold; Dean, Bonnie; Jun, Hannah; Acosta, Pilar; Gonzalez-Perez, Maria Alejandra; Wersun, Alec; and Gibbons, Belinda (2020) "Advancing Sustainability Education in Business Studies through Digital Service Learning," American Business Review. Vol. 23 : No. 2 , Article 5. DOI: $10.37625 / a b r .23 .2 .283-299$

Available at: https://digitalcommons.newhaven.edu/americanbusinessreview/vol23/iss2/5 


\section{Advancing Sustainability Education in Business Studies through Digital Service}

Learning

\section{Authors}

Stephanie Perkiss, Stephanos Anastasiadis, Leopold Bayerlein, Bonnie Dean, Hannah Jun, Pilar Acosta, Maria Alejandra Gonzalez-Perez, Alec Wersun, and Belinda Gibbons 
Advancing Sustainability Education in Business Studies through Digital Service Learning

American Business Review Nov. 2020, Vol.23(2) $283-299$

(c) The Authors 2020, CC BY-NC ISSN: 2689-8810 (Online) ISSN: $0743-2348$ (Print)

\title{
Stephanie Perkiss a , Stephanos Anastasiadis b, Leopold Bayerlein c, Bonnie Dean a, Hannah Jun d, Pilar Acosta e, Maria Alejandra Gonzalez-Perez ${ }^{f}$, Alec Wersun $\mathrm{g}$, and Belinda Gibbons ${ }^{\text {a }}$
}

https://doi.org/10.37625/abr.23.2.283-299

\begin{abstract}
To support the development of a society that is attuned to the challenges presented by sustainable development, it is vital that higher education business students understand the value of sustainability, and act in a way that is consistent with these values. This paper explores a sustainability-focused experiential learning activity through investigating the utility of an emerging form of service learning in the digital space for developing global citizens. The paper presents an international case study of educators who employed digital service learning in various business education contexts. The research reports on the perceptions of higher education students in relation to their awareness, critical thinking and action for sustainability. The paper has practical contributions in identifying an opportunity for implementing sustainability curriculum into higher education for business.
\end{abstract}

\section{KEYWORDS}

Business education, Digital service learning, Sustainability, WikiRate

\section{INTRODUCTION}

In recent years, there has been a global call for business, accounting and management education (herein, business education) to undergo curriculum transformation to account for the ever-increasing need for sustainability education (Bayerlein 2015; Boyce 2004; Dean et al. 2018a; Saravanamuthu 2015). Higher education professionals are faced with the complexity of designing curricular that engages students in sustainability issues and that develops core competencies to prepare graduates for organisational sustainability challenges (Cebrian and Junyent 2015). In order to do so, educators are required to think beyond discursive disciplinary boundaries that define the knowledge and skills of one profession from another (Boyce 2004), into a transdisciplinary space where the future world of work is progressing.

\footnotetext{
a University of Wollongong, Australia

b Polizeiakademie Niedersachsen, Germany

c University of New England, Australia

d Ewha Woman's University, South Korea

e Universidad ICESI, Colombia

f Universidad EAFIT, Colombia

g Glasgow Caledonian University, Scotland, UK

Corresponding Author:

Perkiss (sperkiss@uow.edu.au)
} 
Embedding sustainability into curricular requires rethinking ingrained, disciplinary siloed approaches to teaching business education, which includes reframing the way teachers design and deliver information (Anastasiadis et al. 2020). Impactful learning about sustainability “won't happen though if we simply tell students about it, or we leave them to their own devices to read it in a book or on the Internet" (Dean et al. 2018b, 403). Teaching sustainability requires an approach that is crossdisciplinary, discovery-based and experiential (Bayerlein 2015; Dean et al. 2018b; Perkiss et al. 2019). Purposeful design of pedagogical activities is essential to engage students in learning that is experienced first-hand, has personal meaning, and that can translate into effective social change. By providing opportunities for students to develop their own opinions around social and environmental organisational performance, they learn to construct professional identities and a sustainably ethos (Wersun et al. 2019).

This paper explores the perceptions of students who participated in a unique initiative that was designed to foster the development of students' sustainability mindsets through an emerging experiential learning method, digital service learning (DSL). DSL is a new experiential model of service learning that integrates classroom learning and community service in a virtual space (Strait and Nordyke 2015). Because DSL is conducted in an online environment, it offers the potential for engaging large numbers of students in various locations to serve community goals, without the logistical and resourcing barriers of traditional service learning. To date, however, the value of DSL has been largely unexplored as a new pedagogical approach of experiential learning. More so, there is a growing need to study DSL because of its strong potential to contribute to and impact students' learning experience especially in times of disruption to standard service learning. For example, DSL is particularly valuable for sustainability education in the current time of crisis caused by the COVID-19 pandemic, where traditional face-to-face education is, in many cases, impossible.

The study in this paper focuses on evaluating students' experiences of a DSL sustainability activity that was implemented across seven institutions in six countries. While each institution adapted the activity independently based on their context, common to each site of learning was students' engagement in the same online platform and service to a global community. The overarching aim of the activity was to foster students' awareness of sustainability and its complexity and to develop critical thinking around sustainability and how it is presented in the public space. The activity also aimed to support students to reflect on their own actions as global citizens to develop an intention to take action on sustainable development. A review of student responses in relation to the learning experience of the DSL activity revealed several key findings: learning skills by doing; enhanced critical thinking; impactful learning; and awareness and intention to act.

This paper garners insight into student learning of sustainability as experienced through DSL pedagogy. The paper explores the utility of DSL as a useful medium for sustainability education to aid the development of sustainability-minded and action-oriented professionals. The remainder of the paper is structured as follows. The next section provides a discussion on DSL as a pedagogical approach before introducing the study, the DSL activity and the sites of research. The paper offers findings around the utility of DSL in sustainability education, reflections from the students and concluding remarks on the future of business education.

\section{EXPERIENTIAL LEARNING FOR FOSTERING GLOBAL CITIZENS}

Recently, educators across business disciplines have advocated for experiential and active learning pedagogies for teaching sustainability education (Dean et al. 2018b; Gonzalez-Perez et al. 2019; Perkiss 
et al. 2019; Shephard et al. 2019). Experiential learning involves more than participation in an activity itself, it involves iterative processes of reviewing, reflecting and planning for action as a result of engagement (Kolb and Kolb 2017). Experiential learning helps students to create personally meaningful and relevant behavioural change, by moving beyond an understanding of something towards devising and executing purposeful actions. This pedagogical movement is increasing as students are "being oriented toward a future where knowing how to learn using immersive, interactive and reflective activities eclipses the current focus on knowing what to memorize" (Shephard et al. 2019, 10).

Adopting experiential learning approaches for sustainability education requires a reorientation of content and presentation of information (Kurthakoti and Good 2019). The unidirectional nature of traditional methods of business education, that focus on single and specific discipline, fail to address the training graduates need in order to work and develop solutions around sustainability issues in complex environments (Sibbel 2009). Pedagogy for sustainability is best aligned with strategies that develop students' ability to think in new ways and from different worldviews as global citizens (Stubbs and Cocklin 2008). This requires teachers to model and teach skills such as self-reflexivity, critique, and social action or engagement in the classroom (Rusinko 2005). Therefore, sustainability education requires staff to generate, experiment with and adopt innovative teaching and learning practices (Barth and Rieckmann 2012).

Several assessments and activities are commonly used for experiential learning in business education, including case studies, simulations and games, group projects, internships and study abroad or field trips (Kurthakoti and Good 2019). In a review of sustainability education in business curriculum many of these methods were identified in the literature, notably case method, action/experiential learning, service learning, problem-based learning, and other (seminar, lectures, videos, group discussions) (Figueiro and Raufflet 2015). Common to these teaching activities was the shift from content-centered techniques to more student-centred approaches, intended to cultivate responsible citizens and the development of employability skills such as problem solving and critical thinking (Figueiro and Raufflet 2015).

\section{DIGITAL SERVICE LEARNING}

An emerging pedagogical approach in sustainability education is service learning (Figueiro and Raufflet 2015). Service learning represents an activity that integrates classroom learning and community service into one coherent student-learning experience that results in simultaneous outcomes for students and society (Deeley 2015; Hebert and Hauf 2015; Still and Clayton 2004). It strives to "systematically implement academic content, reflection, evaluation, and experiential activities with a community benefit outcome" (Lypka 2018,3). Service learning is a form of experiential learning, combining processes of student reflection on real-world experiences to develop knowledge and understanding of community and citizenship (Deeley 2015). It is designed to stimulate students' appetite for social justice, encourage critical thinking, take purposeful action and enhance practice as community-minded individuals (Deeley, 2015). In business education, service-learning projects can promote effective learning of sustainability (Brower 2011; Rusinko 2010). They enable students to engage with different stakeholders in industry, communities and countries and be exposed to lifechanging experiences (Brower 2011). Students can expand their perception of sustainability from organisations to society overall or more broadly, facilitating perceptions of learning away from "for the community" towards learning "with the community" (Brundiers et al. 2010). 
While service learning focuses on developing engaged citizens, the expansion of service learning in the digital space opens possibilities to account for digital citizenship as well as global responsibility that are rapidly becoming central to civic life (Shah et al. 2018). Digital citizenship describes appropriate and responsible conduct online but also the astute and discerning awareness of online information. Developing these skills is important for business graduates as today's students are a "product of the digital revolution" (Kurthakoti and Good 2019, 33). Learning through online engagements can be transformative, for "when students see themselves as part of a virtual community network that builds on the rich assets, internal agency, and relationships of community members, they are better equipped to be competent communicators and ethical decision-makers looking for opportunity wherever they go" (Shah et al. 2018, 215).

DSL encompasses the characteristics of service learning, yet because it is facilitated online it offers a much wider reach, with the potential to impact global communities (Strait and Nordyke 2015). In doing so, it also avoids some of the challenges typically experienced in service learning relating to finding opportunities for students to contribute to local communities. DSL has largely been driven by distance education, which includes online cross-country mentoring, communication through wikis (Walsh 2010), online English for Speakers of Other Languages instructor sites (Lypka 2018) and platforms enabling collaboration for rural high school and tertiary sector students (Shah et al. 2018).

DSL offers many benefits to learners due to the geographical boundlessness of students and community organisations. Students can conduct service anywhere, connect to and engage with communities in other countries and access otherwise isolated communities or international populations, regardless of location (Strait and Nordyke 2015). Yet despite these benefits, educators have also offered some limitations of DSL, such as issues with connectivity or Internet access and students' need for support and guidance in the online space (Shah et al. 2018). Such challenges can potentially be addressed through the provision of support structures (Bayerlein and Jeske 2018), including providing specific, regular feedback, technical support, as well as opportunities for online discussions to connect students with each other and the teacher (Shah et al. 2018).

As sustainability education increasingly becomes embedded into business education, opportunity arises for scholars and educators to explore various pedagogical approaches for nurturing informed global citizens. While service-learning shifts into the digital space, DSL is one such pedagogical approach that could offer new ways and approaches for learning sustainability that has yet to be explored. This paper now turns to outline a case study of a global project that investigated the utility of DSL across continents to develop business students' understanding of sustainability.

\section{METHOD}

The aim of this research was to explore student learning of sustainability through a DSL activity. The DSL activity employed in this study was facilitated through a platform called WikiRate.

\section{WIKIRATE AS DSL}

WikiRate was launched as a non-profit organisation in 2013 with the aim of making companies better through the increased adoption of the Sustainable Development Goals (SDGs) (WikiRate 2020). The WikiRate tool is a public repository of sustainability and corporate social responsibility (CSR) data used for analysis and decision-making. It has over 46,000 companies on its public platform (WikiRate 2020). For each listed company, information is sourced and organised in accordance with the targets and 
indicators of the SDGs ${ }^{1}$, and other frameworks, including the Global Reporting Initiative (GRI) ${ }^{2}$. WikiRate is used by stakeholders to view corporate impacts and actions according to their social and environmental activities; track, evaluate and rate this performance; and push companies towards better disclosure, transparency and accountability (Mills et al. 2016).

The WikiRate platform is peer-produced and the available data crowdsourced (WikiRate 2020). Thus, WikiRate has many potential external contributors and users, such as higher education students, academics and non-governmental organisations, representing a range of stakeholders. Access to the platform is free and accommodates any stakeholder with a smart device and an internet connection. To aid the initial design and accumulation of sustainability data onto the platform, WikiRate supports higher education projects. As a result, academics across institutions worldwide have embedded student-engagement projects that use WikiRate in curricula (WikiRate 2020; Dean et al. 2018b). The WikiRate classroom project has been identified and analysed as an experiential learning construct (see Dean et al. 2018b and Perkiss et al. 2019). However, it is also a prosocial project, with a community service component, and thus an example of DSL.

Sourcing information on WikiRate has a community service component as the provision of crowdsourced sustainability data makes it easier for stakeholders to make decisions. For example, information can be obtained in a more useful and comparable format based on specific indicators, without the need to filter through large sustainability reports (Mills et al. 2016). Using WikiRate in higher education develops students' understanding of the opportunities and challenges of meaningful change relating to sustainable development. It further allows students to research and engage in social change through the making transparent of corporate sustainability data and promotes personal growth through reflection, experience and an intention to act in the context of sustainable development.

In order to evaluate the utility of DSL as a way of generating students' awareness of sustainability, the authors launched a global research project that aimed to embed WikiRate in business curriculum. The courses in which WikiRate was embedded included accounting, business, business capstone, CSR, ethics, management, project work and sustainability, each with varying student enrolment numbers and learning outcomes. While each course had varying learning outcomes and assessment components, all participating faculty required students to research corporate reports and disclosures alongside specific metrics and indicators of the SDGs using the WikiRate platform as a learning environment. The leadership and instruction of the WikiRate team was a key constant across all institutions.

Each course instructor could adapt the WikiRate DSL activity to the specific course and its competences to be developed. For each institution and course, a WikiRate program manager developed a "project page" and students were invited to join and research their project. Specific details of each project varied slightly. For instance, at one Colombian university (University C, see Table 1 below) the WikiRate project was the final project of the undergraduate course, and students had to demonstrate an understanding of the importance of business leaders' contribution to sustainable development. The project accounted for $25 \%$ of the students' final grade. Students received the following instructions ${ }^{3}$ :

\footnotetext{
${ }^{1}$ See https://www.un.org/sustainabledevelopment/sustainable-development-goals/

${ }^{2}$ See https://www.globalreporting.org/

3 The detailed set of instructions were constructed by the WikiRate team and shared among global institutions. All participating institutions in this research had the same set of instructions for their courses. The variations were based on the specific assessment details and questions asked of students in their analysis independent of the use of the WikiRate platform.
} 
- Create a team of 3-4 students.

- Identify five companies in the same sector that report financial and non-financial data.

- Extract and synthesise data from the latest three available communication of progress (COPs) or annual sustainability report of the five companies.

- Become familiar with the WikiRate platform (http://wikirate.org) 4

- From each report enter extracted data in the platform according to the SDG metrics.

- Analyse the inputted data in the platform, identifying the main contributions to the SDGs of the sector (local and internationally) to which the company belongs.

Following, students were asked to respond to questions including:

a. In which way do the sustainability reports of the companies studied reflect their contribution to SDGs?

b. Which of the companies analysed stands out for their contribution to SDGs? Why?

c. What essential aspects of this industry are imperative to contribute to SDG but are not reported?

d. What data is being considered in Colombia to report advances in SDGs?

e. Which are the companies' business contributions to the SDGs at the national level?

A similar method was adopted for the other participating institutions. As teaching sustainability requires an approach that is cross-disciplinary, the course instructors at each institution created crossdisciplinary student teams. Various university courses embedded the activity and participated in the research, including business capstones, broad CSR or ethics courses, those focused on project work and an introductory subject. Each course had diverse students from business disciplines and other majors. Slight variations in the tasks inside the DSL activity were observed in that, for example, some students focused on researching organisations' disclosures around specific metrics, including climate change or human rights metrics. Some students researched companies that were headquartered in the institution's country, for example in University G, South Korea. Other students researched one organisation over a range of SDG metrics or targets, for example at University A, Australia (see Heithaus et al. 2018 and Perkiss et al. 2018 for other examples of using WikiRate).

Notwithstanding the variations of research per institution, all students involved in the global WikiRate project sourced sustainability information from corporate webpages, reports and other locations where required or directed, and uploaded their findings to WikiRate. Therefore, regardless of the institution or course level, each student participated in an activity that used WikiRate according to the same methodology. After students' engagement with the common, global DSL activity, they were invited to participate in a survey on their experiences, feedback and knowledge development.

\section{PARTICIPANTS}

The institutions that participated in the DSL activity were from Austria, Australia, Colombia, South Korea and the UK (England and Scotland). Each institution was an early adopter of the WikiRate DSL activity and a member of the Principles of Responsible Management Education (PRME), and therefore, had signed a declaration to promote sustainability education in their classrooms. It is important to note that each participating course had varying numbers of students (see Table 1 which details the type of course, class size and country).

4 The WikiRate team provide teaching resources, including some PDF files which are too long to share in this research paper, but other resources/help was available online, see, for example https://wikirate.org/Using_WikiRate. 
Table 1. The global case study partners, the course in which WikiRate was implemented, the number of participating students in 2018 and the number of participating students in the survey per institution.

\begin{tabular}{|c|c|c|c|}
\hline $\begin{array}{l}\text { University, } \\
\text { Country }\end{array}$ & Course description, level & $\begin{array}{l}\text { No. of } \\
\text { students }\end{array}$ & $\begin{array}{c}\text { No. of } \\
\text { students that } \\
\text { participated in } \\
\text { survey }\end{array}$ \\
\hline \multirow{2}{*}{$\begin{array}{l}\text { University A, } \\
\text { Australia }\end{array}$} & $\begin{array}{l}\text { Business capstone, final year, } \\
\text { undergraduate }\end{array}$ & 42 & 35 \\
\hline & $\begin{array}{l}\text { Introductory accounting, first year, } \\
\text { undergraduate }\end{array}$ & 760 & 321 \\
\hline $\begin{array}{l}\text { University B, } \\
\text { Austria }\end{array}$ & $\begin{array}{l}\text { Case studies in business and sustainability, } \\
\text { final year, undergraduate }\end{array}$ & 82 & 76 \\
\hline $\begin{array}{l}\text { University C, } \\
\text { Colombia }\end{array}$ & CSR course, final year, undergraduate & 27 & 2 \\
\hline $\begin{array}{l}\text { University D, } \\
\text { Colombia }\end{array}$ & Ethics and CSR, final year, undergraduate & 300 & 5 \\
\hline $\begin{array}{l}\text { University E, } \\
\text { England }\end{array}$ & $\begin{array}{l}\text { Project work for managers - sustainability } \\
\text { and society, postgraduate }\end{array}$ & 130 & 3 \\
\hline $\begin{array}{l}\text { University F, } \\
\text { Scotland }\end{array}$ & $\begin{array}{l}\text { Sustainability, corporate responsibility and } \\
\text { ethics, final year, undergraduate }\end{array}$ & 220 & 95 \\
\hline $\begin{array}{l}\text { University G, } \\
\text { South Korea }\end{array}$ & $\begin{array}{l}\text { Special topics in international business, } \\
\text { postgraduate }\end{array}$ & 14 & 12 \\
\hline Total students & & 1,575 & 549 \\
\hline
\end{tabular}

Participants were all higher education students studying in a variety of degree programs, at both undergraduate and graduate levels. English was the language of instruction in all cases. The course levels ranged from first-year undergraduate to post-graduate masters. Students were enrolled in programs ranging from Bachelor of Commerce, through Bachelor of Business Administration, to Master of International Management. A small number of participating undergraduate students were enrolled in Law, Arts, Mathematics and Engineering degrees. Overall, there were $91 \%$ undergraduate students and $9 \%$ graduate students.

The study represents a significantly global mix of student voices. Of the responses, the following information was received on students' country of birth: Australia (52\%); Austria (13\%); UK - England and Scotland (7\%); China and Hong Kong (5\%); Vietnam (4\%); and small numbers from Bangladesh, Brazil, Colombia, France, Germany, India, Lithuania, Mongolia, New Zealand, Nepal, Philippines, Portugal, Scandinavian countries, Serbia, South Africa, South Korea, USA; with 9\% undisclosed. There was a near equal gender balance. Notwithstanding this data, our intention was not to separate responses and analysis by country, institution, demographics or elsewise, but to present an evaluation of a learning experience concerned with a timely global issue: sustainability 5 .

\footnotetext{
5 This is an important point for the current paper's findings. As mentioned earlier in the Methods section, the aim of the paper was to report on the learning outcomes of WikiRate as a DSL activity in educating students on sustainability. While we acknowledge that each institution has variations in their specific project designs and assessment, each institution was led by the WikiRate team and followed the same research, data inputting and analysis method. Hence, the findings of this research are not separated by country or institution but provide a general overview of the impact of the DSL activity in educating sustainability.
} 


\section{DATA COLLECTION AND ANALYSIS}

The global survey was administered at the end of the DSL activity at each institution. The link to the survey was made available to all enrolled students in the participating courses in an email and/or by being posted on the course's online learning platform. Participation was voluntary and students were free to leave the survey at any time. From a total enrolment of 1,575 students globally from the seven partner institutions, we received 549 student responses, a response rate of 35 percent $(549 / 1,575)$. Each of the participating higher education institutions was represented in the student survey responses to a varying degree (see Table 1 for the breakdown of student responses per institution).

The full survey consisted of 22 open and closed survey questions. Questions included how students used the WikiRate platform; how they were assessed; and the challenges they faced when using the WikiRate platform (See Appendix 1 for a fuller list of survey questions). The questions analysed in relation to the current paper attempted to collect student perceptions on organisational sustainability and transparency practices and reflections on their own changes in knowledge related to sustainability. Questions included: Comment on the degree to which companies are providing adequate disclosure relating to their social and environmental performance. And, how have your thoughts/attitudes on the sustainable development goals (SDGs), sustainability, and corporate social responsibility (CSR) been impacted or changed since engaging in this activity?

Thematic analysis was used to analyse the survey data. Thematic analysis involves a process of making sense of participants' responses around the set case study or phenomena (Boyatzis 1998). Overall, the researchers' aim was to uncover student perceptions of sustainability and specifically the SDGs and reflect on how this might affect the future. This study comprised multiple researchers, and thus participants' responses to the survey questions were analysed in two main stages. First, the lead researchers conducted their own independent thematic analyses. This involved reading, coding and categorising the material. Subsequent comparison revealed a very high inter-rater consensus on the main themes. The second stage followed after a meeting between the researchers and involved an iterative process of consolidating and fine-tuning the initial analyses into the four main themes that are presented in this paper.

\section{FINDINGS}

A review of student responses revealed several categories of interest: learning skills by doing; enhanced critical thinking; impactful learning; and awareness and intention to act. Data is presented here to illustrate each theme ${ }^{6}$.

\section{LEARNING SKILLS BY DOING}

Learning skills by doing covers research skills, teamwork and problem solving. Working with real-life material through the digital WikiRate environment at a deeper level was also shown to facilitate greater awareness of the topic of sustainability that underlies the SDGs and the DSL exercise. As one respondent put it, "CSR [corporate social responsibility] and the SDGs are a lot more than what they appear to be at face value".

Respondents self-reported that they valued the practical nature of the exercise. This required a range of skills needing independent development, such as interpreting data and problem solving. Students illustrated learning skills by doing arguing, for example, "[you] had to source the information yourself. This pushed the need to research more in-depth. More personal work"; "[that it] made the

\footnotetext{
${ }^{6}$ Note that the data - student survey responses - have been edited for grammar and understandability.
} 
whole experience more hands-on, as it was a real-life business and it enabled us as students to see the reality of social accountability and the lack of disclosure that a lot of businesses experienced"; and that "having to do my own research benefited my ability to comprehend the information I was finding, and use it to support my theories". Other responses included "improved problem-solving abilities; and "allowed me to analyse and interpret data".

Lipman's $(1987,5)$ functional definition of critical thinking includes three characteristics: "selfcorrective thinking," "thinking with criteria" and "thinking that is sensitive to context". Developing and strengthening the learning skills by doing is an important basis for developing students' critical thinking ability.

\section{ENHANCED CRITICAL THINKING}

Sustainability is a complex issue that future leaders need to be aware of and think critically about; and it is through education that the SDGs can be understood and realised (PRME 2019). The theme of enhanced critical thinking encompasses critical thinking, enhanced analytical thinking, appreciation for complexity and greater skepticism of companies and their actions.

The self-reported data shows that respondents' engagement with the DSL activity is clearly associated with enhanced critical-thinking skills, a key component of service learning. For example: "It made me evaluate and seriously think about the effects businesses have on our society and the environment, rather than just traditional classroom activities"; "I do not believe they [CSR disclosures] are effective, as companies are still choosing to ignore the metrics and SDGs put forward"; and "I don't feel surprised that companies are sometimes doing the bare minimum, as often pursuing social or environmental health is fundamentally at odds with making the most money possible".

The activity gave the students a space to "learn differently" and encourage "self-reliability", for example, "I have definitely become more aware of CSR issues and the international efforts that have been taken to increase the accountability of businesses. I have also become aware of the need to not always take things at face value". It was also interesting to read the students' responses and their own theories on disclosure, i.e. "reporting the bare minimum" and indicating instances of greenwashing through largely reporting positive sustainability impacts. For example:

It enabled me to understand the actual impact businesses are having in the world of CSR and on SDGs and see beyond the face value of things (i.e. question whether companies are actually achieving the SDGs through assessing each metric individually). I gained a deeper understanding through this activity.

Such analytical and critical-thinking skills on the SDGs and business impact will be vital for future business professionals. As one student reflected, "this project may prove beneficial in that future businesswomen and businessmen will learn to see sustainability as an essential criterion for operating $a$ business". 


\section{IMPACTFUL LEARNING}

The impactful learning theme is associated with an enhanced learning experience. In the activity, the use of real-life company data and the fact that respondents' research was publicly available online, therefore increasing personal accountability and impact, contributed to making the exercise more impactful, and hence global community service oriented. For example, one student reported:

Applying real-life data to an authentic website felt empowering and also reinforced the idea of transparency and accountability on our side as students, as we were individually responsible for searching, delivering and applying accurate information regarding the business's performance. Inputting real-life data also gave me a greater awareness that businesses do not always disclose all relevant information to the public.

One student stated that, "it was a privilege to help and inform other people. It made what we were doing feel important". While others reported that, "it allows us to see that what we learn truly impacts the world. It gives us an experience that goes beyond the classroom to ensure that the learning we are doing has a place in the cultural climate of the world", and that the activity "enabled a deeper understanding into current issues around sustainability, which made the type of learning more meaningful."

An exercise that students find meaningful is beneficial for learning because more meaningful material is likely to enhance student motivation and satisfaction. Student satisfaction is positively related to student learning (Gibson 2010), whilst motivation is known to have a positive impact on deep learning in particular (see Naidoo 2015). A meaningful activity also contributes to an intention to take action.

\section{AWARENESS AND INTENTION TO ACT}

The final theme, an awareness and intention to act, is concerned with the heightened awareness and broader knowledge of sustainability and the SDGs, enhanced respect for responsible companies and a changed perspective on respondents' own actions. Most respondents in this study ( $82 \%$ or $440 / 549$ ) perceived their thoughts and attitudes on the SDGs to have been affected or changed through engaging in the WikiRate activity. For example, one student reported, "it has created a deeper awareness of the issues pertinent to society and the duty I have as part of society to encourage corporations to disclose information and act responsibly in their environmental and social activities".

Many students self-reported an enhanced respect for sustainable-focused companies. For example:

I didn't know about the UNGC [United Nations Global Compact] and SDGs before this class. To be honest, I also didn't really pay attention to them; they were really broad and appointed topics. But after some intense searching on the SDGs and on CSR reports, I really respect companies that try to improve their CSR, that work on sustainability and caring for the planet and the people living on it. It isn't just a matter of environmental care, but also human care and the green economy. 
A limited number of students appeared to have been entirely unaffected by the exercise. For example, one student reported, "to be frank, my thoughts on SDGs have not changed much because I acknowledged the importance of them [the SDGs] before working on this activity"; and several others responded "not much" or "it hasn't been impacted" to the question: how have your thoughts/attitudes on the SDGs... been impacted or changed since engaging in this activity? Nonetheless, at the very least, a lot of students offered continued support for particular action on the SDGs. Additionally, many students self-reported an enhanced awareness of sustainability and the SDGs, and a more questioning mindset, for example, "I have a much more socially responsible outlook since engaging in this activity as I understand that business has a greater effect on sustainability then I first thought".

The analysis identified another group of students that illustrated they had become more aware of, and sensitised to, sustainability and the SDGs. These students reported an intention or proposal for future action. This result was the desired learning outcome for students involved in the activity responses on an intention to act take a variety of intended avenues. For example, actions taken within an employing organisation, for example, "[the activity] made me realise that I want to work for a firm that is a strong believer in the SDGs. The SDGs have a major impact on our society, and I can help minimise the negative sustainability impacts". It also allowed students to plan for what to look for in an employer or if starting their own business, for example, "[the activity] has made me more aware of the large impact that businesses have on the environment", and "has allowed me to reflect on my own actions as well and be more aware for the future in the areas that I may work". Finally, students reported an intension to act through proposing changes to personal choices as a consumer, for example, "[the activity] made me more aware of the importance of sustainability which may impact my choice to consume particular brands and products" and "I will definitely have a think before acting, especially environmentally-wise".

\section{DISCUSSION AND LESSONS LEARNT}

Assigning a DSL activity using WikiRate can be useful in educating sustainability concepts in business subjects and driving sustainable action of participating students. DSL has the potential to promote prosocial action through increasing students' knowledge of ethics and social responsibility (Deeley 2015). The data show that the DSL activity was useful in helping a large proportion of students develop awareness of the SDGs, and to think critically about them. Student discussion supported the "service learning" aspect of the activity, suggesting that the real-world nature of the exercise and public contribution increased its meaningfulness.

The researchers found that the DSL activity appeared to have facilitated participants' appreciation of sustainability and the SDGs as a wicked problem; and informed their reaction to it. A wicked problem is one with no obvious solution, involving many stakeholders, and for which a solution requires behavioural change (Ferlie et al. 2011). When prompted to discuss sustainability and the perceived learning outcomes of the DSL activity, not a single respondent portrayed sustainability and CSR as a simple matter. Thus, we witness that many students understand the practical challenges of sustainability, and more that propose to apply their increased knowledge and awareness to solve the challenges of transparency and actively participate in furthering the SDG agenda. As one student put it, "I have gained a new perspective of how companies are or are not accountable/transparent in their progress towards the goals, something I will consider when deciding which companies to support".

The evidence suggests that the exercise prompted the desired outcome - action, with some respondents planning to take action in response to their learning. Our thinking here is that students 
who have fully engaged with the activity are likely to have a substantially improved sense of their own competence on sustainability and the SDGs, to the benefit of society. Such students will use the DSL activity as a stepping-stone to personal transformation, greater understanding of the issue and be prompted to action. For example, students indicated that the activity was "empowering [and they felt they were] making a difference and actually helping others". One student reported that the value of the DSL activity on their learning "was associated with the inputting of real-life data compared to traditional classroom activities [and there was] the feeling of self-satisfaction knowing that I was contributing/adding value to greater benefit society". An implication of the activity beyond student satisfaction could be that students are more likely to be encouraged to keep learning. Where students are satisfied with their learning there is an expectation that they will continue their studies. This could mean students advancing towards their degree, positivity impacting student retention; choosing to study a further degree, for example a Masters; or choosing to learn more about sustainability .

Unsurprisingly, not all students showed evidence of having achieved the desired "action" outcome through the DSL activity. This could be due to a lack of connectedness or being less engaged in the activity, or simply not spending enough time on WikiRate. Fortunately though, the community benefit was achieved by their participation. While many students reported that the use of WikiRate had a substantial effect on their understanding and awareness of the SDGs, and encouraged critical thinking and problem solving, not all reached the stage of undertaking action in this area. Thus, our lessons here are that a successful DSL activity on sustainability requires significant scaffolding to engage with the SDGs in a meaningful way; and, that significant effort is required to get students to feel "connected" to society vis-à-vis traditional face-to-face service learning. As a result, it could be beneficial for the WikiRate platform to provide a more informed narrative of community engagement and communication among participants beyond SDG metrics and numerical performance. This may include, for example, a place for discussion and understanding of the motives of different individuals' participation and creating greater value and sense of service between students and the global community.

\section{CONCLUDING COMMENTS}

To effectively teach sustainability, an approach that is cross-disciplinary, discovery-based and experiential is required (Dean et al. 2018b; Perkiss et al. 2019). This paper reported on a global partnership to evaluate student learning of sustainability through an emerging pedagogical approach, digital service learning (DSL). A survey was conducted to collect student perceptions on organisational sustainability practices through contributing to an international online platform that serves as organisational transparency for a global community. Analysis of the survey data revealed four interrelated themes: learning skills by doing; enhanced critical thinking; impactful learning; and awareness and intention to act. Based on students' interaction with the activity, we found evidence that new awareness of sustainability led to new critical thinking for respondents, and that new critical thinking was associated with a self-reported intention to take action.

While not all students achieved the desired "taking action" outcome of the DSL activity, we have illustrated an opportunity for sustainable development and the SDG education, and to aid the development of sustainability-minded and action-oriented professionals. This case study is an open project that anyone can use, given WikiRate is a crowdsourced public platform. Thus, we have provided a case study that will assist educators in thinking of and preparing other SDG-focused

\footnotetext{
7 While we do not have evidence on student retention or students continuing their studies as a result of the WikiRate activity, we can hypothesize that satisfaction raises the likelihood of continuing studies.
} 
educational activities, especially in times of crisis where traditional service learning is disrupted, for example during the COVID-19 pandemic. A limitation of this research is the different response rate per university, which means there is a higher representation of some of the participating institutions in the findings. Further the overall rate of return on the questionnaire is low. The implication of this is the potential limiting recall of the DSL activity and that there may be voluntary response bias. Another limitation is that, although the study is global, given the courses that embedded the DSL activity had different enrolment numbers, some countries are represented more than others, albeit each institution itself has a high number of international students.

Educators have a responsibility to engage students through thought-provoking, innovative and action-developing activities, in order to strive for a more sustainable future (Wersun et al. 2019). Educational activities on sustainability must be transformative to encourage self-awareness to aid competence and transformation (Anastasiadis et al. 2020; Wersun et al. 2019). As this paper has discussed, DSL is one experiential learning approach that engages students in real-world activities for the benefit of society and that develops their critical thinking and awareness and intension to act sustainably. We encourage future research and pedagogical innovation into different experiential methods to empower business students with sustainability knowledge and action. 


\section{REFERENCES}

Anastasiadis, S, Perkiss, S., Dean, B.A., Bayerlein, L., Gonzalez-Perez, A., Wersun, A., Jun, H. and Gibbons, B. "Teaching sustainability: complexity and compromises", Journal of Applied Research in Higher Education, 2020, preprint. DOI: 10.1108/JARHE-02-2020-0029

Barth, M. and Rieckmann, M. "Academic staff development as a catalyst for curriculum change towards education for sustainable development: an output perspective", Journal of Cleaner production, 2012, 26: pp. 28-36

Bayerlein, L. "Curriculum innovation in undergraduate accounting degree programmes through 'virtual internships"', Education + Training, 2015, 57(6): pp. 673-684.

Bayerlein, L. and Jeske, D. "Student learning opportunities in traditional and computer-mediated internships", Education + Training, 2018, 60(1): pp. 27-38.

Boyatzis, R. Transforming qualitative information: Thematic analysis and code development. 1988. Thousand Oaks, CA: Sage Publications.

Boyce, G. "Critical accounting education: teaching and learning outside the circle", Critical Perspectives on Accounting, 2004, 5(4-5): pp. 565-596.

Brower, H. H. "Sustainable development through service learning: A pedagogical framework and case example in a third world context". Academy of Management Learning \& Education, 2011, 10, 5876.

Brundiers, K., Wiek, A., and Redman, C. L. "Real-world learning opportunities in sustainability: from classroom into the real world", International Journal of Sustainability in Higher Education, 2010, 11(4): pp. 308-324.

Cebrian, G., and Junyent, M. "Competencies in education for sustainable development: Exploring the student teachers' views”. Sustainability, 2015, 7(3): pp. 2768-2786.

Dean, B. A., Perkiss, S., Simic Misic, M. and Luzia, K. "Transforming accounting curricula to enhance integrative learning”, Accounting \& Finance, 2018a, DOI: 10.1111/acfi.12363.

Dean, B., Gibbons, B. and Perkiss, S. "An experiential learning activity for integrating the Sustainable Development Goals into business education”, Social Business, 2018b, 8(4): pp. 387-409.

Deeley, S. J. Critical perspectives on service-learning in higher education. 2015. London: Palgrave Macmillan.

Ferlie, E., Fitzgerald, L., McGivern, G., Dopson, S. and Bennett, C. "Public policy networks and 'wicked problems': A nascent solution?” Public Administration: An International Quarterly, 2011, 89(2): pp. 307-324.

Figueiro, S.P. and Raufflet, E. "Sustainability in higher education: a systematic review with focus on management education". Journal of Cleaner Production., 2015, 106, 22-33.

Gibson, A. "Measuring business student satisfaction: a review and summary of the major predictors", Journal of Higher Education Policy and Management. 2010, 32(3): pp. 251-259.

Gonzalez-Parez, M. A., Lynden, K. and Taras, V. The Palgrave Handbook of Learning and Teaching International Business and Management. 2019. Palgrave Macmillan: Switzerland.

Heithaus, T., Mills, R. and Perkiss, S. "Disclosure and reporting against the Sustainable Development Goals: Connecting new stakeholders to sustainability data". 2018. PRME and WikiRate e.V. Germany, Berlin. Available at: https://tinyurl.com/y7s6e24u.

Hebert, A. and Hauf, P. "Student learning through service learning: Effects on academic development, civic responsibility, interpersonal skills and practical skills", Active Learning in Higher Education, 2015, 16(1): pp. 37-49.

Kolb, A. B., \& Kolb, D. A. "Experiential learning theory as a guide for experiential educators in higher education”. ELTHE: A Journal for Engaged Educators, 2017, 1(1): pp. 7-44. 
Kurthakoti, R. and Good, D. C. "Evaluating outcomes of experiential learning: An overview of available approaches". In M. A. Gonzalez-Perez, Taras, V., and K. Lynden (eds), 2019, The Palgrave handbook of learning and teaching international business and management. UK: Palgrave Macmillan.

Lipman, M. (1987), “Critical thinking: What can it be?” Analytic Teaching, 1987, 8(1): pp. 5-12.

Lypka, A. E. "Infusing participatory digital service-learning to deepen community-engaged professional excellence: Triumphs and challenges. Reading Matrix", An International Online Journal, 2018, 18(2): pp. 77-93.

Mills R., De Paoli, S., Diplaris, S., Gkatziaki, V., Papadopoulos, S., Prasad, S., McCuttchen, E., Kapadia, V. and Hirche, P. "WikiRate.org - Leveraging collective awareness to understand companies' environmental, social and governance performance". In Bagnoli F. et al. (Eds), Internet Science, 2016, Springer, Cham, pp. 74-88,

Naidoo, D. “Understanding non-traditional PhD students habitus - implications for PhD programmes", Teaching in Higher Education 2015, 20(3): pp. 340-351.

Perkiss, S., Dean, B. A., Gibbons, B., Heithaus, T., Wersun, A., Gonzalez-Perez, M. A., Anastasiadis, S., Acosta, P., Mesick, R., Jun, H. and Mills, R. "WikiRate student engagement report: International case studies". 2018, University of Wollongong, WikiRate \& PRME: Wollongong, Australia. Available at: https://ro.uow.edu.au/buspapers/1503/.

Perkiss, S., Dean, B. A., Gibbons, Gonzalez-Perez, M. A., B., Heithaus, T., Acosta, P., Mills, R., Anastasiadis, S., Bayerlein, L., Wersun, A., Mesick, R. and Jun, H. "Learning experientially for corporate social responsibility: International applications of the WikiRate project". In M. A. Gonzalez-Perez, Taras, V., and K. Lynden (eds), The Palgrave handbook of learning and teaching international business and management. 2019. UK: Palgrave Macmillan.

Principles of Responsible Management Education (PRME), Available at: https://www.unprme.org/ (accessed 5 March 2019).

Rusinko, A. C. "Using quality management as a bridge in educating for sustainability in a business school", International Journal of Sustainability in Higher Education, 2005, 6(4): pp. 340-350.

Rusinko, C. A. "Integrating sustainability in higher education: a generic matrix". International Journal of Sustainability in Higher Education, 2010, 11(3): pp. 250-259.

Saravanamuthu, K. "Instilling a sustainability ethos in accounting education through the transformative learning pedagogy: A case-study", Critical Perspectives on Accounting 2015, 32: pp. 1-36.

Shah, R. W., Troester, J. S., Brooke, R., Gatti, L., Thomas, S. L. and Masterson, J. "Fostering eABCD: Asset-based community development in digital service-learning", Journal of Higher Education Outreach and Engagement 2018, 22(2): pp. 189-221.

Shephard, I., Leigh, E. and Davies, A. "Revisiting the impact of philosophies and theories in experiential learning”. In M. A. Gonzalez-Perez, Taras, V., and K. Lynden (eds), The Palgrave handbook of learning and teaching international business and management. 2019. UK: Palgrave Macmillan.

Sibbel, A. "Pathways towards sustainability through higher education", International Journal of Sustainability in Higher Education, 2009, 10(1): pp. 68-82.

Still, K. and Clayton, R. "Utilizing Service-Learning in Accounting Programs", Issues in Accounting Education 2004, 19(4): pp. 469-486.

Strait, J. and Nordyke, K. eService-learning: Creating experiential learning and civic engagement through online and hybrid courses. 2015. Sterling, VA: Stylus.

Stubbs, W. and Cocklin, C. "Teaching sustainability to business students: shifting mindsets", International Journal of Sustainability in Higher Education, 2008, 9(3): pp. 206-221. 
Wersun, A., Dean, B. A., Mills, R., Perkiss, S., Acosta, P., Anastasiadis, S., Gibbons, B., Gonzalez-Perez, M. Alejandra., Heithaus, T., Jun, H., Mesicek, R. H. and Bayerlein, L. "An exploration of student learning for sustainability through the WikiRate student engagement project". The International Journal of Management Education 2019,17(3), pp. 1-12.

Walsh, L. "Constructive interference: Wikis and service learning in the technical communication classroom”, Technical Communication Quarterly 2010, 19(2): pp. 184-211.

WikiRate. Available at: www.wikirate.org (accessed 5 August 2020). 


\section{APPENDIX}

Appendix 1. Sample of Survey Questions used in the research project

What is your degree and major area of study?

What level of study are you completing?

How much time have you spent using WikiRate overall?

Was the work around WikiRate assessed?

What was the value to your learning of inputting real-life data compared to traditional classroom activities?

Did you use the data you collected on WikiRate for any analyses? Did you use data collected by other users? Please describe.

Comment on the degree to which companies are providing adequate disclosure relating to their social and environmental performance.

How have your thoughts/attitudes on the sustainable development goals (SDGs), sustainability, and corporate social responsibility (CSR) been impacted or changed since engaging in this activity?

Comment on your role in contributing to the global sustainability goals and whether you felt this was beneficial outside your classroom activity.

What challenges did you face during the WikiRate classroom activity?

Do you intend to use WikiRate in the future? How?

Comment on anything else relevant to your assessment, learning and overall experience throughout the WikiRate activity. 